\title{
IDENTIFIKASI INTERAKSI MANUSIA DAN KOMPUTER BERBASIS COMPUTER VISION SYNDROME PADA UNIT REFINERY CENTRAL CONTROL ROOM
}

\author{
Muchamad Sugarindra ${ }^{1}$, Zuhdi Allamsyah ${ }^{2}$ \\ Jurusan Teknik Industri, Fakultas Teknologi Industri, Universitas Islam Indonesia ${ }^{1,2}$ \\ Jl. Kaliurang Km.14,5 Sleman, Yogyakarta 55584. \\ E-mail : sugarindra@uii.ac.id ${ }^{1)}$,zuhdiallamsyah@gmail.com ${ }^{2)}$
}

\begin{abstract}
Technology usage for elevating work productivity still cannot be separated from human control. Therefore, company performance will be affected by the operator's quality. Computer interaction, as an example of technology used, is dominating the work performed. Continuous and repetitive used will affect the occupational health. Hence, it will increase the risk of Computer Vision Syndrome (CVS). Computer Vision Syndrome (CVS) is defined as a collection of symptoms related to eyes caused by computer usage and affected by several factors. Those factors can be divided into individual and external factors.

The problem of this research is to determine whether there is a relationship between CVS with the internal and external factors. The type of research is non experimental quantitative with correlational research design and cross sectional approach. While the respondents are twelve operators of Refinery Central Control Room (RCCR). Spearman Rho test is used to find relationship among variables.

The results from this research indicate that there is correlation between age and the resulting CVS symptoms with the value of $p$ is 0,04 ( $p<0$ 05). But, there are no correlation between CVS and other factors (eye glasses, length of work duration, break time, eye sides distance). Not all internal and external factors have correlation with the accuracy of CVS. This Research shows correlation between internal factors and CVS. It was aging. Aging is degenerative processes which lower the body function periodically. Therefore, there are correlation between age and CVS. But, there are not for other factors.
\end{abstract}

Keywords: Computer Vision Syndrome, Human Interaction.

\section{PENDAHULUAN}

Kemajuan dunia industri dan cepatnya inovasi teknologi yang semakin pesat membuat perusahaan menjadi lebih kompetitif dalam menghadapi persaingan. Perusahaan selalu dituntut untuk dapat mencapai tujuan dengan meningkatkan kinerja peusahaan secara optimal. Kolaborasi yang baik penggunaan teknologi dan pengelolaan sumber daya manusia akan bisa memberikan dampak yang signifikan bagi perusahaan.

Teknologi otomasi merupakan salah satu teknologi informasi yang digunakan untuk optimasi produksi sehingga hasilnya akan lebih cepat. Namun, penggunaan teknologi tersebut masih menggunakan Sumber Daya Manusia (SDM) sebagai pengontrol. Tugas SDM tersebut bertindak sebagai operator yang menjalankan dan mengendalikan proses produksi. Oleh karena itu kualitas operator dapat mempengaruhi kinerja perusahaan. DCS (Distributed Control System) merupakan suatu ruangan yang dijadikan sebagai sistem control otomatis yang terpusat.

Ruangan tersebut adalah tempat kerja operator dimana operator bekerja dengan menggunakan komputer sepanjang hari. Operator berperan penting dalam pekerjaan ini, sehingga kualitas kerjanya harus diperhatikan. Untuk mencapai kualitas kerja yang baik dipengaruhi oleh beberapa faktor. Faktor - faktor tersebut meliputi faktor individu (usia, penggunaan kacamata, lama bekerja dengan komputer, durasi bekerja dengan komputer, lama istirahat setelah penggunaan komputer) dan faktor eksternal (pencahayaan, suhu ruangan, posisi bagian atas monitor terhadap ketinggian horizontal mata, jenis komputer dan polaritas monitor) (Miller 2001; Izquerdo, 2011; Thompson, 
1998; Bhanderi et al., 2008; Kanitkhar et al., 2005; Rossignol et al., 1987.

Hal - hal tersebut dapat mempengaruhi kesehatan kerja. Komputer sebagai alat kerja operator merupakan salah satu hal-hal yang mempengaruhi kesehatan kerja. Penggunaan komputer yang terus - menerus beresiko terjadinya Computer Vision Syndrome (CVS). CVS adalah suatu kumpulan gejala yang berhubungan dengan mata disebabkan karena penggunaan komputer (Wimalasundera, 2006). Pada saat menggunakan komputer biasanya seseorang akan terfokus pada layar komputer dalam waktu yang cukup lama, hal tersebut dapat menyebabkan masalah pada mata seperti mata kering, kemerahan, iritasi, mata lelah, mata tegang, pandangan kabur sementara, peka terhadap rangsang cahaya dan masalah otot sebagai akibat penggunaan komputer (Wimalasundera, 2006; Ansel, 2005). Menurut Garg \& Rosen (2008) beberapa orang berusia 30 - 40 tahun mengeluhkan penurunan kemampuan dalam memfokuskan obyek dekat dalam waktu sementara dan dikemudian hari terjadi penurunan akomodasi mata. Operator yang bekerja di unit Refinery Central Control Room (RCCR) juga mengalami keluhan yang sesuai dengan CVS.

Dari latar belakang diatas muncul rumusan masalah dan tujuan penelitian yaitu untuk mengetahui apakah ada hubungan antara usia dengan keluhan CVS, penggunaan kacamata dengan keluhan CVS, lama bekerja dengan keluhan CVS, durasi bekerja menggunakan komputer dengan keluhan CVS, jarak lama istirahat dengan keluhan CVS, jarak penglihatan dengan keluhan CVS.

\section{KAJIAN PUSTAKA}

\subsection{Pengertian Computer Vision Syndrome}

Menurut American Optometric Association, Computer Vision Syndrome (CVS) adalah sekumpulan gejala yang terjadi pada mata yang disebabkan oleh penggunaan komputer, tablet, handphone atau alat elektronik lainnya. Sedangkan menurut Garg \& Rosen (2008) CVS adalah sebuah kondisi yang terjadi pada orangorang yang bekerja pada monitor komputer. CVS disebabkan oleh penurunan refleks berkedip saat bekerja dalam waktu yang lama dan fokus pada layar komputer. Frekuensi berkedip normal adalah 16 - 20 kali per menit. Studi menunjukkan frekuensi berkedip menurun hingga 6 - 8 kali per menit pada pekerja yang menggunakan komputer. Sebagai tambahan, pemfokusan dalam jarak dekat untuk durasi yang lama memaksa kerja dari otot siliaris pada mata. Beberapa orang dengan umur sekitar 30-40 tahunan mengeluhkan ketidak-mampuan dalam memfokuskan obyek - obyek dekat setelah bekerja dalam waktu yang singkat, yang berakhir pada penurunan mekanisme fokus akomodasi dari mata dan presbyopia (Garg \& Rosen, 2008).

\subsection{Penyebab Computer Vision Syndrome}

Menurut (Ansel, 2005) penyebab CVS antara lain kelelahan otot ekstraokuler dan intraokuler, penurunan kedipan mata, mata kering, stress pada otot mata yang berulang, penggunaan kacamata atau lensa kontak dan kelainan refraksi.

\subsection{Gejala Computer Vision Syndrome}

Menurut Blehm et al. (2005) Gejala CVS dikategorikan menjadi empat kategori antara lain :

a. Gejala astenopia, gejala astenopia terdiri dari mata lelah, mata tegang, mata kering, dan nyeri kepala.

b. Gejala yang berkaitan dengan permukaan okuler. Gejalanya berupa mata teriritasi. Penyebab kejadian mata teriritasi dapat disebabkan karena pantulan cahaya dan bayangan yang terbentuk pada monitor (Talwar et al., 2009).

c. Gejala visual, gejala visual terdiri dari penglihatan kabur, penglihatan ganda, presbyopia dan kesulitan dalam memfokuskan penglihatan.

d. Gejala ekstraokuler, gejala ekstraokuler terdiri dari nyeri bahu, nyeri leher, dan nyeri punggung. 


\subsection{Faktor Resiko Computer Vision Syndrome}

\subsubsection{Faktor Individu}

Faktor individu meliputi :

a. Usia ; Produksi air mata mengalami penurunan dengan meningkatnya usia. Studi yang dilakukan oleh Bhanderi et al. (2008) menunjukan hubungan yang signifikan antara pengaruh usia dengan meningkatnya kejadian CVS. Dalam penelitian tersebut dilaporkan bahwa individual yang berusia diatas dari 45 tahun dua kali lebih beresiko menderita CVS dibandingkan individual yang berumur 15 sampai 25 tahun.

b. Penggunaan kacamata ; Penggunaan kacamata yang bertujuan untuk mengoreksi gangguan refraksi juga merupakan salah satu faktor risiko dari CVS. Dalam penelitian didapatkan bahwa dari 136 sample, ditemukan keluhan penglihatan kabur pada 19 subyek (59,4\%), mata tegang saat menggunakan Video Display Terminal (VDT) sebanyak 18 subyek (56,3\%), dan keluhan sakit kepala ditemukan pada 20 subyek (62,5\%). Hasil ini menunjukan bahwa terdapat keluhan astenopia yang signifikan antara pengguna VDT yang menggunakan kacamata dengan yang tidak menggunakan kacamata.

c. Lama bekerja ; Bhanderi et al. (2008) melaporkan bahwa angka kejadian CVS lebih tinggi pada individual yang menggunakan komputer kurang dari lima tahun.

d. Lama istirahat ; Menurut Thompson (1998) penggunakan komputer yang diselingi istirahat selama 5 sampai 10 menit secara teratur memberikan hasil yang lebih baik dibandingkan istirahat setiap dua atau tiga jam. Namun pola istirahat yang sering digunakan adalah dengan sistem 20-20-20 yaitu istirahat selama 20 detik dengan melihat obyek berjarak minimal 20 kaki / 6 meter setiap 20 menit bekerja dan kedipkan mata sesering mungkin. e. Durasi bekerja ; Studi menunjukan bahwa terdapat hubungan antara tingginya prevalensi gejala visual terhadap individual yang menggunakan komputer lebih dari 4 jam dalam sehari. (Rossignol et al., 1987). Hal yang sama juga dilaporkan oleh Kanitkar et al. (2005) bahwa durasi penggunaan komputer sangat berhubungan dengan gejala yang muncul pada mata dan lamanya gejala tersebut hilang. Penggunaan komputer tanpa diselingi waktu istirahat dapat menurunkan kemampuan akomodasi mata yang berakibat terjadinya gejala dari CVT.

\subsubsection{Faktor Lingkungan}

Faktor Lingkungan meliputi:

a. Jarak penglihatan ; Mata memiliki Resting Point of Accommodation (RPA) yaitu titik dimana mata akan fokus tanpa suatu stimulus visual atau ketika dalam keadaan gelap yaitu antara 20 - 37 inci $(50,8$ cm- 93,98 cm $)$. Kebiasaan memfokuskan obyek penglihatan pada jarak yang lebih pendek dari RPA yang ideal, seperti pada pekerja komputer, dapat memicu stress pada mata. Chiemeke et al. (2007) melaporkan bahwa keluhan gangguan penglihatan lebih banyak pada pekerja dengan jarak penglihatan kurang dari 10 inci $(25,4$ $\mathrm{cm}$ ) (Gambar 1). Studi oleh Taptagaporn et al. (2007) melaporkan bahwa jarak penglihatan yang direkomendasikan adalah $50-70 \mathrm{~cm}$ dan studi lain menyatakan bahwa semakin jauh monitor diletakkan $(90-100 \mathrm{~cm})$ maka dapat meminimalisasi timbulnya keluhan penglihatan. 


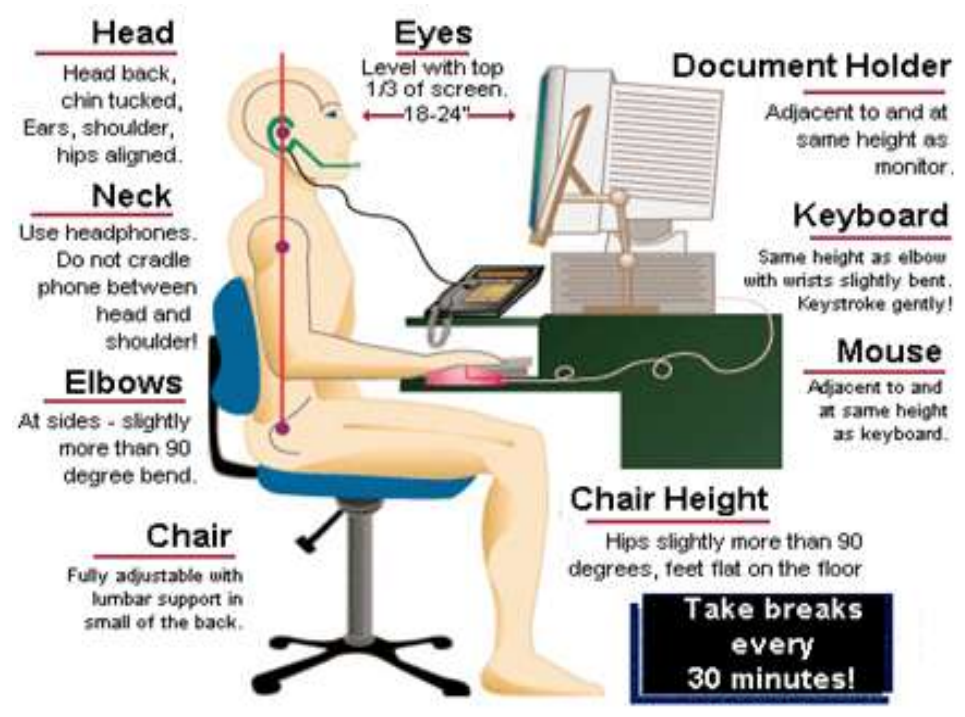

Gambar 1. Jarak Penglihatan.

(www.apakabarsidimpuan.com)

b. Posisi bagian atas monitor terhadap ketinggian horizontal mata ; Posisi monitor yang baik adalah posisi yang ketinggian horizontal sejajar dengan mata. Posisi monitor yang lebih tinggi dari posisi mata akan menyebabkan sudut penglihatan mata lebih besar dan menurunkan frekuensi berkedip. Hal ini dapat menyebabkan mata menjadi kering (Miller, 2001). Sudut penglihatan merupakan faktor terpenting terhadap terjadinya CVS karena besarnya sudut penglihatan dapat mempengaruhi munculnya gejala CVS. Sudut penglihatan ke arah bawah sebesar $100-200$ merupakan sudut penglihatan yang ideal.

c. Jenis komputer ; Pada awalnya komputer menggunakan monitor jenis Cathode Ray Tube (CRT) atau lebih dikenal komputer tabung atau layar cembung namun monitor jenis ini dapat menimbulkan kelelahan pada mata sehingga komputer tabung saat ini lebih jarang digunakan. Solusi yang dapat dilakukan untuk menanggulangi masalah tersebut adalah dengan pemasangan penapis antiglare pada monitor komputer

\begin{abstract}
tabung, namun komputer tabung dengan penapis antiglare dapat mengurangi kelelahan mata pada pekerja pengguna komputer. Penapis antiglare dapat mengurangi pantulan cahaya (Hanum, 2008). Pengguna komputer sekarang lebih banyak yang menggunakan komputer Flat Panel Monitor (FPM) atau komputer layar datar. Komputer jenis dapat meminimalisasi kelelahan mata, oleh karena bentuknya yang datar maka pantulan cahaya dari luar lebih sedikit. Komputer layar datar juga lebih praktis karena tidak memerlukan penapis antiglare.
\end{abstract}

\section{METODE PENELITIAN}

Jenis penelitian ini merupakan penelitian kuantitatif non eksperimen dengan desain penelitian korelasi. Pendekatan penelitian adalah cross sectional. Data diambil dengan menggunakan kuisioner dimana isi kuisioner mencakup hal - hal yang sesuai dengan rumusan masalah dan tujuan penelitian. Pertanyaan kuisioner mencakup usia, penggunaan kacamata, durasi bekerja menggunakan komputer, jarak lama istirahat, jarak penglihatan terhadap komputer dan keluhan CVS. 
Tabel 1. Data demografi responden RCCR

\begin{tabular}{|c|c|c|}
\hline Kategori & $\begin{array}{l}\text { Jumlah } \\
\text { (n) }\end{array}$ & Persentase $(\%)$ \\
\hline \multicolumn{3}{|l|}{ Usia (tahun) } \\
\hline$\geq 40$ & 2 & 17 \\
\hline$<40$ & 10 & 83 \\
\hline \multicolumn{3}{|c|}{ Penggunaan kacamata } \\
\hline Iya & 1 & 8 \\
\hline Tidak & 11 & 92 \\
\hline \multicolumn{3}{|c|}{ Lama bekerja dengan komputer (tahun) } \\
\hline$\geq 5$ & 5 & 42 \\
\hline$<5$ & 7 & 58 \\
\hline \multicolumn{3}{|c|}{ Durasi bekerja dengan komputer (jam) } \\
\hline$\geq 4$ & 9 & 75 \\
\hline$<4$ & 3 & 25 \\
\hline \multicolumn{3}{|c|}{$\begin{array}{c}\text { Lama istirahat setelah penggunaan } \\
\text { komputer (menit) }\end{array}$} \\
\hline$\geq 10$ & 7 & 58 \\
\hline$<10$ & 5 & 42 \\
\hline \multicolumn{3}{|c|}{ Jarak penglihatan $(\mathrm{cm})$} \\
\hline$\geq 50$ & 8 & 67 \\
\hline$<50$ & 4 & 33 \\
\hline \multicolumn{3}{|c|}{$\begin{array}{c}\text { Posisi bagian atas monitor terhadap } \\
\text { ketinggian horizontal mata }\end{array}$} \\
\hline Lebih Tinggi & 0 & 0 \\
\hline Lebih Rendah & 12 & 100 \\
\hline \multicolumn{3}{|l|}{ Jenis Komputer } \\
\hline Layar Datar & 12 & 100 \\
\hline Layar Cembung & 0 & 0 \\
\hline
\end{tabular}

Tabel 2. Keluhan CVS pada responden di RCCR

\begin{tabular}{l|c|c|c|c}
\hline \multirow{2}{*}{ Keluhan } & \multicolumn{2}{c|}{ Ya } & \multicolumn{2}{c}{ Tidak } \\
\cline { 2 - 5 } & n & \% & n & \% \\
\hline Mata lelah dan tegang & 5 & 42 & 7 & 58 \\
Mata berair & 3 & 25 & 9 & 75 \\
Mata kering dan teriritasi & 2 & 17 & 10 & 83 \\
Mata melihat kabur & 2 & 17 & 10 & 83 \\
Nyeri kepala & 1 & 8 & 11 & 92 \\
Mata melihat kembar & 1 & 8 & 11 & 92 \\
Kesulitan memfokuskan pandangan & 1 & 8 & 11 & 92 \\
\hline
\end{tabular}

Responden berjumlah 12 orang yang merupakan operator pada di RCC. Analisis univariat ditampilkan dalam bentuk distribusi frekuensi dan persentase, seadngkan analisis bivariat yang berupa korelasi menggunakan uji statistik SPSS. Uji statistik yang digunakan adalah Spearman Rho untuk mengetahui hubungan antara dua variabel.

\section{HASIL DAN PEMBAHASAN}

\subsection{Data Demografi Responden}

Menurut usia, karakteristik responden yang berusia $\geq 40$ tahun sebanyak $17 \%$ dan $<40$ tahun sebanyak 83\%. Penggunaan kacamata sebanyak $8 \%$ responden menggunakan kacamata dan $92 \%$ responden tidak menggunakan kacamata. Lama bekerja dengan menggunakan komputer terdapat $42 \%$, 
Tabel 3. Hubungan Antara Usia dengan Keluhan Computer Vision Syndrome pada Operator di RCCR

\begin{tabular}{|c|c|c|c|c|c|}
\hline \multirow{3}{*}{ Usia (tahun) } & \multicolumn{4}{|c|}{ Keluhan Computer Vision Syndrome } & \multirow{3}{*}{ P value } \\
\hline & \multicolumn{2}{|c|}{$\mathbf{Y a}$} & \multicolumn{2}{|c|}{ Tidak } & \\
\hline & n & $\%$ & $\mathbf{n}$ & $\%$ & \\
\hline$\geq 40$ & 1 & 20 & 1 & 14 & \\
\hline$<40$ & 4 & 80 & 6 & 86 & 0.04 \\
\hline Total & 5 & 100 & 7 & 100 & \\
\hline
\end{tabular}

Tabel 4. Hubungan Antara Penggunaan Kacamata dengan Keluhan Computer Vision Syndrome pada Operator di RCCR

\begin{tabular}{|c|c|c|c|c|c|}
\hline \multirow{3}{*}{ Penggunaan Kaca Mata } & \multicolumn{4}{|c|}{ Keluhan Computer Vision Syndrome } & \multirow{3}{*}{ P value } \\
\hline & \multicolumn{2}{|c|}{ Ya } & \multicolumn{2}{|c|}{ Tidak } & \\
\hline & $\mathbf{n}$ & $\%$ & $\mathbf{n}$ & $\%$ & \\
\hline Ya & 0 & 0 & 1 & 14 & \\
\hline Tidak & 5 & 100 & 6 & 86 & 0.70 \\
\hline Total & 5 & 100 & 7 & 100 & \\
\hline
\end{tabular}

responden $\geq 5$ tahun, sedangan $58 \%$ responden menggunakan komputer $<5$ tahun.

Durasi jam bekerja ada $75 \%$ responden $\geq 4$ jam dan $25 \%$ responden $<4$ jam dalam bekerja menggunakan komputer. Lama istirahat setelah penggunaan komputer $\geq 10$ menit terdapat $58 \%$ sedangkan $<10$ menit terdapat $42 \%$. Jarak penglihatan $\geq 50 \mathrm{~cm}$ sebanyak $67 \%$ sedangkan $<50 \mathrm{~cm}$ sebanyak $33 \%$. Posisi bagian atas monitor terhadap ketinggian horizontal mata seluruh responden sejajar lebih rendah dengan mata yaitu $100 \%$. Sedangkan jenis komputer yang digunakan responden adalah $100 \%$ menggunakan koputer layar datar (Tabel 1).

\subsection{Keluhan Computer Vision Syndrome}

Keluhan CVS pada responden di RCCR adalah sebagai berikut: mata lelah dan tegang ada $42 \%$ responden sedangkan yang tidak mengalami sebanyak 58\%; mata berair dialami oleh $25 \%$ responden sedangkan $75 \%$ tidak mengalami mata berair; mata kering dan teriritasi dialami oleh $17 \%$ responden sedangkan $83 \%$ tidak mengalami; mata melihat kabur dialami oleh $17 \%$ responden sedangkan $83 \%$ tidak mengalami; Nyeri kepala dialami oleh $8 \%$ responden sedangkan $92 \%$ tidak mengalami nyeri kepala; mata melihat kembar dialami oleh pandangan dialami oleh $8 \%$ responden sedangkan 92\% tidak mengalami (Tabel 2).

\subsection{Hubungan Antara Usia dengan} Keluhan Computer Vision Syndrome

Hasil uji statistik menunjukkan hubungan antara usia dengan keluhan CVS dengan $p$ value 0.04 (Tabel 3). Hal tersebut sesuai dengan penelitian Bhanderi et al. (2008) bahwa usia berpengaruh terhadap kejadian CVS. Usia tua atau yang disebut dengan aging akan mengalami degenerasi fungsi pada mata sehingga akan meningkatakan resiko terjadinya CVS (Tortora \& Derickson, 2009). Selain itu pada aging mulai ada penurunan fungsi yang ditunjukkan dengan keluhan presbiopi atau mata tua (Tortora \& Derickson, 2009).

\subsection{Hubungan Antara Penggunaan Kacamata dengan Keluhan Computer Vision Syndrome \\ Pada penelitian ini didapatkan hasil} bahwa tidak ada hubungan antara penggunaan kacamata dengan keluhan CVS dengan $p$ value 0.44 (Tabel 4). Penggunaan kacamata yang dimaksud adalah bagi operator yang memiliki kelainan refraksi, 
Tabel 5. Hubungan Antara Lama Bekerja dengan Keluhan Computer Vision Syndrome pada Operator di RCCR

\begin{tabular}{|c|c|c|c|c|c|}
\hline \multirow{3}{*}{$\begin{array}{c}\text { Lama Bekerja } \\
\text { Dengan Komputer } \\
\text { (tahun) }\end{array}$} & \multicolumn{4}{|c|}{ Keluhan Computer Vision Syndrome } & \multirow{3}{*}{$P$ value } \\
\hline & \multicolumn{2}{|c|}{ Ya } & \multicolumn{2}{|c|}{ Tidak } & \\
\hline & $\mathrm{n}$ & $\%$ & $\mathbf{n}$ & $\%$ & \\
\hline $\begin{array}{l}\geq 5 \\
<5\end{array}$ & $\begin{array}{l}1 \\
4\end{array}$ & $\begin{array}{l}20 \\
80\end{array}$ & $\begin{array}{l}6 \\
1\end{array}$ & $\begin{array}{l}86 \\
14\end{array}$ & 0.39 \\
\hline Total & 5 & 100 & 7 & 100 & \\
\hline
\end{tabular}

Tabel 6. Hubungan Antara Durasi Bekerja Menggunakan Komputer dengan Keluhan Computer Vision Syndrome pada Operator di RCCR

\begin{tabular}{|c|c|c|c|c|c|}
\hline \multirow{3}{*}{$\begin{array}{c}\text { Durasi Bekerja } \\
\text { Menggunakan } \\
\text { Komputer (jam) }\end{array}$} & \multicolumn{4}{|c|}{ Keluhan Computer Vision Syndrome } & \multirow{3}{*}{ P value } \\
\hline & \multicolumn{2}{|c|}{$\mathbf{Y a}$} & \multicolumn{2}{|c|}{ Tidak } & \\
\hline & $\mathbf{n}$ & $\%$ & $\mathbf{n}$ & $\%$ & \\
\hline $\begin{array}{l}\geq 4 \\
<4\end{array}$ & $\begin{array}{l}2 \\
3\end{array}$ & $\begin{array}{l}40 \\
60\end{array}$ & $\begin{array}{l}7 \\
0\end{array}$ & $\begin{array}{c}100 \\
0\end{array}$ & 0.44 \\
\hline Total & 5 & 100 & 7 & 100 & \\
\hline
\end{tabular}

Tabel 7. Hubungan Antara Lama Istirahat dengan Keluhan Computer Vision Syndrome pada Operator di RCCR

\begin{tabular}{c|c|c|c|c|c}
\hline \multirow{2}{*}{$\begin{array}{c}\text { Lama Istirahat } \\
\text { (menit) }\end{array}$} & \multicolumn{4}{|c|}{ Keluhan Computer Vision Syndrome } & \multirow{2}{*}{ P value } \\
\cline { 2 - 5 } & $\mathbf{n}$ & $\mathbf{\%}$ & $\mathbf{n}$ & $\mathbf{\%}$ & \\
\cline { 2 - 5 } & $\mathbf{n}$ & 20 & 6 & 86 & \multirow{2}{*}{0.67} \\
\hline 10 & 1 & 80 & 1 & 14 & \\
\hline Total & 4 & $\mathbf{1 0 0}$ & $\mathbf{7}$ & $\mathbf{1 0 0}$ & \\
\hline
\end{tabular}

Tabel 8. Hubungan Antara Jarak Penglihatan dengan Keluhan Computer Vision Syndrome pada Operator di RCCR

\begin{tabular}{c|c|c|c|c|c}
\hline \multirow{2}{*}{$\begin{array}{c}\text { Jarak Penglihatan } \\
(\mathbf{c m})\end{array}$} & \multicolumn{4}{|c|}{ Keluhan Computer Vision Syndrome } & \multirow{2}{*}{ P value } \\
\cline { 2 - 5 } & $\mathbf{n}$ & $\mathbf{\%}$ & $\mathbf{n}$ & $\mathbf{\%}$ & \\
\cline { 2 - 5 } & 2 & 40 & 7 & 100 & \multirow{2}{*}{0.6} \\
\hline 50 & 3 & 60 & 0 & 0 & \\
\hline Total & $\mathbf{5}$ & $\mathbf{1 0 0}$ & $\mathbf{7}$ & $\mathbf{1 0 0}$ & \\
\hline
\end{tabular}

dalam penelitian ini hanya ada 1 responden yang menggunakan kacamata sehingga menunjukkan tidak ada hubungan antara penggunaan kacamata dengan keluhan CVS.

\subsection{Hubungan Antara Lama Bekerja dengan Keluhan Computer Vision Syndrome}

Pada penelitian ini tidak terdapat hubungan antara lama bekerja dengan keluhan CVS dengan $p$ value 0.39 (Tabel 5). Bhanderi et al. (2008) melaporkan bahwa angka kejadian CVS lebih tinggi pada individual yang menggunakan komputer kurang dari lima tahun. Pada penelitian ini ada beberapa responden yang menggunakan komputer lebih dari 5 tahun dan ada yang kurang (Tabel 1). Dari data tersebut menunjukkan bahwa lamanya menggunakan komputer tidak ada hubungan dengan keluhan CVS. 


\subsection{Hubungan Antara Durasi Bekerja Menggunakan Komputer dengan Keluhan Computer Vision Syndrome}

Pada penelitian ini menunjukkan bahwa tidak ada hubungan antara durasi bekerja dengan keluhan CVS dengan $p$ value (0.44) (Tabel 6). Hal ini tidak sesuai dengan pernyataan Rossignol et al. (1987) yang menunjukan bahwa terdapat hubungan antara tingginya prevalensi gejala visual terhadap individual yang menggunakan komputer lebih dari 4 jam dalam sehari. Hal yang sama juga dilaporkan oleh Kanitkar et al. (2005) bahwa durasi penggunaan komputer sangat berhubungan dengan gejala yang muncul pada mata dan lamanya gejala tersebut hilang. Hal tersebut mungkin disebabkan bahwa keluhan CVS yang dirasakan responden lebih sedikit dibandingkan dengan yang tidak mengalami keluhan (Tabel 6).

\subsection{Hubungan Antara Lama Istirahat dengan Keluhan Computer Vision Syndrome}

Pada penelitian ini tidak terdapat hubungan antara lama istirahat dengan keluhan CVS dengan $p$ value 0.67 (Tabel 7). Hal ini tidak sesuai dengan pendapat Thompson (1998) bahwa penggunakan komputer yang diselingi istirahat selama 5 sampai 10 menit secara teratur memberikan hasil yang lebih baik dibandingkan istirahat setiap dua atau tiga jam. Namun pola istirahat yang sering digunakan adalah dengan sistem 20-20-20 yaitu istirahat selama 20 detik dengan melihat objek berjarak minimal $20 \mathrm{kaki} / 6$ meter setiap 20 menit bekerja dan kedipkan mata sesering mungkin (Hazarika \& Singh, 2014). Paa penelitian ini tidak menunjukkan hubungan, hal itu mungkin disebabkan karena keluhan CVS lebih sedikit dibandingkan dengan yang tidak mengalami keluhan CVS (Tabel 7).

\subsection{Hubungan Antara Jarak Penglihatan dengan Keluhan Computer Vision Syndrome}

Pada penelitian ini tidak terdapat hubungan antara jarak penglihatan dengan kejadian CVS dengan p value 0.6 (Tabel 8). Dalam penelitian ini jarak penglihatan tidak ada hubungan dengan CVS karena jarak penglihatan ada beberapa responden menggunakan jarak $\geq 50 \mathrm{~cm}$ dan $<50 \mathrm{~cm}$. Hal ini belum sesuai dengan aturan American Otometric Association (1997) bahwa jarak pandang yang ideal berada pada jarak $50-72 \mathrm{~cm}$.

\section{KESIMPULAN DAN SARAN}

\subsection{Kesimpulan}

1. Persentase keluhan Computer Vision Syndrome pada unit Refinery Central Control Room (RCCR) adalah sebagai berikut operator yang mengalami keluhan mata lelah \& tegang (42\%), mata berair $(25 \%)$, mata kering \& teriritasi (17\%), mata melihat kabur/blur $(17 \%)$, nyeri kepala $(8 \%)$, mata melihat kembar (8\%), kesulitan memfokuskan penglihatan (8\%), mata terasa sakit $(0 \%)$.

2. Penelitian ini menunjukkan adanya hubungan antara usia dengan keluhan Computer Vision Syndrome dengan $\mathrm{p}$ value $0.04(\mathrm{p}<0.05)$.

3. Penelitian ini menunjukkan tidak ada hubungan antara penggunaan kacamata dengan Computer Vision Syndrome dengan $\mathrm{p}$ value $0.7(\mathrm{p}>0.05)$.

4. Penelitian ini menunjukkan tidak ada hubungan antara lama bekerja dengan Computer Vision Syndrome dengan $\mathrm{p}$ value 0.39 ( $\mathrm{p}>0.05)$.

5. Penelitian ini menunjukkan tidak ada hubungan antara durasi bekerja dengan Computer Vision Syndrome dengan $\mathrm{p}$ value $0.44(\mathrm{p}>0.05)$. 
6. Penelitian ini menunjukkan tidak ada hubungan antara lama istirahat dengan Computer Vision Syndrome dengan $\mathrm{p}$ value $0.67(\mathrm{p}>0.05)$.

7. Penelitian ini menunjukkan tidak ada hubungan antara jarak penglihatan dengan Computer Vision Syndrome dengan $\mathrm{p}$ value $0.6(\mathrm{p}>0.05)$.

\subsection{Saran}

1. Bagi Perusahaan

a. Memberikan pengendalian secara Administrative Control, berupa poster peringatan mengenai teknis kesehatan kerja yang dipasang pada setiap dinding ruangan.

b. Mengikuti regulasi yang telah diterbitkan oleh lembaga yang berwenang.

2. Bagi Responden

Pekerja pengguna komputer hendaknya melakukan tindakan pencegahan dan deteksi dini dari sindrom ini antara lain :

a. Mengatur pola istirahat saat bekerja dengan komputer dengan sistem 20-2020 yaitu istirahat selama 20 detik dengan melihat objek berjarak minimal 20 kaki / 6 meter setiap 20 menit bekerja.

b. Mengatur jarak pandang antara mata terhadap komputer, jarak pandang terhadap komputer yang baik adalah berkisar $(50-70 \mathrm{~cm})$.

c. Mempertahanan posisi monitor sejajar / lebih rendah dari garis horizontal mata.

3. Bagi Penelitian

Penelitian lanjutan perlu dilakukan dengan menggunakan rancangan penelitian yang berbeda dan variabelvariabel lain, mengingat CVS dipengaruhi oleh multifaktor dan masih banyak faktor yang belum diteliti.

\section{DAFTAR PUSTAKA}

American Optometric Association. 1997. The Effects of Computer Use on Eye Health and Vision.

Ansel, H. 2005. Pengantar Bentuk Sediaan Farmasi. Edisi keempat. Jakarta: UI Press.

Bhanderi, D. J., Choudhary, S., Doshi, V. G., 2008. A community-based study of asthenopia in computer operators. Indian J Ophthalmol. 56:51-5

Blehm, C., Vhisnu, S., Khattak, A., Mitra, S., Yee, R. W., 2005. Computer Vision Syndrome: A Review Survey of ophthalmol. 50(3):253-262.

Chiemeke, S. C., Akhahowa, A. E., Ajayi, O. B., 2007. Evaluation of vision-related problems amongst computer users: a case study of University of Benin, Nigeria, Preceeding of the World Congress on Engineering. Vol. 1, WCE 2007, July 2-4. London. UK. Http://www.iaeng.org/publication/W CE2007/WCE2007-pp217-221.pdf.

Garg, A., \& Rosen, E., 2008. Instant clinical diagnosis in opthalmology anterior segment. Jaypee brothers medical publishers.

Hanum, I. 2008. Efektivitas penggunaan screen pada monitor komputer untuk mengurangi kelelahan mata pekerja call centre di PT Indosat NSR tahun 2008 [tesis]. Medan: Universitas Sumatra Utara.

Http://www.allaboutvision.com/cvs/irritated. htm. Computer Eye Strain: 10 Steps for Relief

Kanitkar, K., Carlson, A.N., \& Richard, Y., 2005. Ocular problems associated with computer use: The everincreasing hours spent in front of video display terminals have led to a corresponding increase in visuals and physical ills. Review of Ophthalmology E-Newsletter, 22(12), 3-4. 
Miller, H. 2001. Vision and The Computerized Office. Available from : www.hermanmiller.fr [ Accessed 6 April 2015].

Rosenfield, M., 2011. Computer vision syndrome: a review of ocular causes and potential treatments. Ophtalmic Physiol Opt. 31(5): 502-15.

Rossignol, A. M., Morse, E. P., Summers, V. M., Pagnotto, L. D., 1987. Visual display terminal use and reported health symptomps among Massachusetts clerical worker. $J$. Occup. Med. 29:112-118.

Talwar, R., Kapoor, R., Puri, K., Bansal, K., Sings., 2009. A study of visual and musculoskeletal health disorders among computer professionals in NCR Delhi. Indian J. Commun. Med. 34(4): 326-328.

Taptagaporn, S., Sotoyama, M., Saito, S., Suzuki, T., Saito, S. Visual comfort in VDT workstation design. $J$ Hum Ergol (Tokyo) 1995; 24:84-8.

Thompson, W.D., 1998, Eye problems and visual display terminals - the facts and the fallacies. Ophthalmic Physiol Opt, 18(2), 111-119.

Tortora, G.J. \& Derrickson, B.H. 2011. Principles of anatomy and physiology. New York: Harper Collins Publisher Inc.

Wimalasundera, S., 2006. Computer Vision Syndrome. Galle Medical Journal Vol 11. No 1.

Www.Apakabarsidimpuan.Com. 